www.jmscr.igmpublication.org

Index Copernicus Value: 79.54

ISSN (e)-2347-176x ISSN (p) 2455-0450

crossrefDOI: https://dx.doi.org/10.18535/jmscr/v7i1.193

\title{
Psychosocial Aspects of Tobacco Use and Nicotine Dependence among Mentally ill Patients Pertaining to Education \& Income Coming to Psychiatry O.P.D.
}

\author{
Authors \\ Dr Sagar Mudgal ${ }^{1 *}$, Dr S.N. Desai ${ }^{2}$, Dr Nikhil Nayar ${ }^{3}$ \\ 1,3 Junior Residents, ${ }^{2}$ Professor of Psychiatry \\ Department of Psychiatry, Index Medical College, Indore, M.P., India \\ *Corresponding Author \\ Dr Sagar Mudgal \\ Email:dr.sagarmudgal@yahoo.com,7024938209
}

\begin{abstract}
Nicotine dependence is a very rampant problem among population in general but specially in mentally ill patients as they are generally vulnerable to this due to various reasons, there have been many studies done on this in the west but very few studies in India, so we conducted a study in the O.P.D. of our hospital, collected sociodemographic data \& applied Modified Fagerstrom's Test of smoking \& smokeless tobacco for Nicotine Dependence, calculated statistical correlates by applying Chi Square test, Mann Whitney scale, Spearman's Coeffecient.
\end{abstract}

Keywords: Nicotine, Mental Illness, Tobacco.

\section{Introduction}

Epidemiological studies in developed, western countries reveal wide variability in tobacco use rates across population subgroups. In many European countries and the U. S., for example, it is known that persons with a history of mental illness are twice as likely as the general population to smoke; in the U. S., persons with a history of mental illness constitute one-half of the domestic tobacco market (Lasser et al., 2000). ${ }^{(1)}$ In contrast, the prevalence of smoking among persons with a mental illness living in developing countries has not been well-studied. The emergence of a global economy, the widespread marketing of tobacco products, and the vulnerability of mentally ill persons make it likely that persons living with a mental disorder in developing countries may also use tobacco products at a disproportionate rate.

India has the world's second largest population, and is projected to surpass China in population by midcentury. In India, tobacco is consumed both through smoked and smokeless forms (Gupta \& Hamner, 1992). ${ }^{(2)}$ Indians smoke tobacco mainly in the form of beedis and cigarettes. The Indian beedi consists of shredded, sun-dried tobacco in small quantities that is hand rolled into a piece of leaf called tendu. Beedis are popular in India and beedi smoking starts at an early age. The smokeless forms of tobacco consumption in India include chewing tobacco and inhalation of snuff. Chewing tobacco is mainly 
consumed in the form of gutkha and zarda. Gutkha, a sweetened mixture of tobacco, betel, and catechu, is sold in brightly colored packets; often used by women and children, it is chewed and then spit out. Zarda, a dried and colored residual tobacco, is obtained by boiling tobacco leaves with spices and lime.

\section{Aims \& Objectives}

To study the consumption of nicotine in any form among the mentally ill patients by studying the socio demographic correlates of the study population calculating the correlates of nicotine use in any form among various mental disorders.

\section{Methodology}

A cross sectional study was done in the Psychiatry O.P.D. of Index Medical College, Hospital \& Research Centre, Indore, M.P. After taking an informed consent, excluding patients of Substance Abuse, their sociodemographic details were collected, F.T.N.D. was applied on them \& statistical correlates calculated.

\section{Table 1}

\begin{tabular}{|c|c|c|c|}
\hline VARIABLE & SUB VARIABLES & \multicolumn{2}{|c|}{ NUMBER $(\%)$} \\
\hline AGE & $18-30$ & \multicolumn{2}{|c|}{$32(31.1)$} \\
\hline & $31-40$ & 44 & $(42.7)$ \\
\hline & $41-50$ & 8 & $(7.8)$ \\
\hline & $51-60$ & \multicolumn{2}{|c|}{$19(18.4))$} \\
\hline SEX & MALE & 78 & (75.7) \\
\hline & FEMALE & 25 & $(25.3)$ \\
\hline MARITAL STATUS & UNMARRIED & \multicolumn{2}{|c|}{$9(12)$} \\
\hline & MARRIED & \multicolumn{2}{|c|}{$66(88)$} \\
\hline EDUCATION & ILLITERATE & \multicolumn{2}{|c|}{$8(7.8)$} \\
\hline & PRIMARY & 17 & $(16.5)$ \\
\hline & MIDDLE & \multicolumn{2}{|c|}{$22(21.4)$} \\
\hline & SECONDARY & \multicolumn{2}{|c|}{$17(16.5)$} \\
\hline & HIGHER SECONDARY & 26 & $(25.2)$ \\
\hline & DIPLOMA & 13 & $(12.6)$ \\
\hline \multirow[t]{5}{*}{ INCOME } & $10-20000$ & 5 & $(4.9)$ \\
\hline & $30-40000$ & 8 & $(7.8)$ \\
\hline & $41-50000$ & \multicolumn{2}{|c|}{$16(15.5)$} \\
\hline & $51-60000$ & 8 & $(7.8)$ \\
\hline & $>70000$ & 66 & $(64.1)$ \\
\hline
\end{tabular}

\section{Results \& Statistics}

Majority of the participants were in the age group of 31-40, married, males and from rural background. Maximum had studied till Higher Secondary. And majority were in the salary group of $>70,000$.

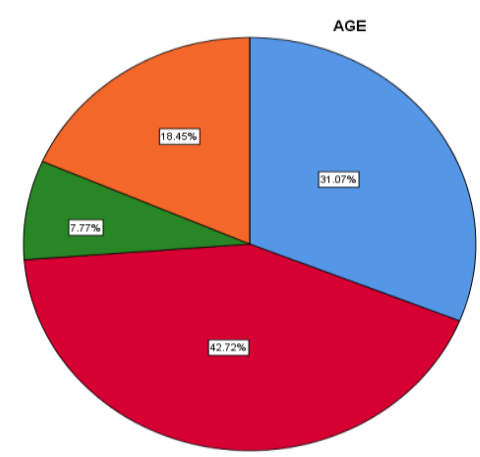

Figure 1 


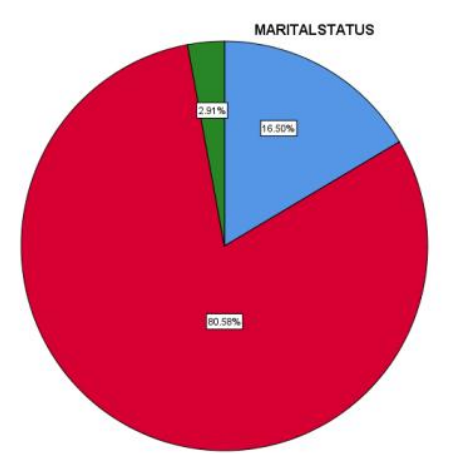

Figure 2

It was found that the more educated lot would prefer to take nicotine is a smoking form while the less educated lot preferred chewable forms of tobacco. (figure 3,7,8) Also people with a higher income also preferred smoking form of tobacco while the less earning lot preferred chewable forms of tobacco. $(4,5,6)$
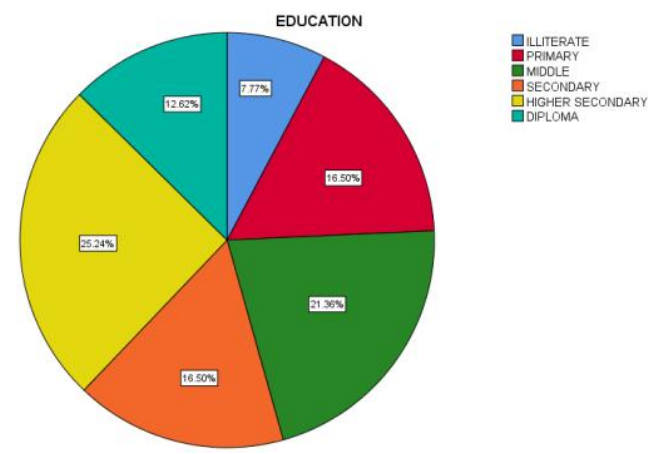

Figure 3
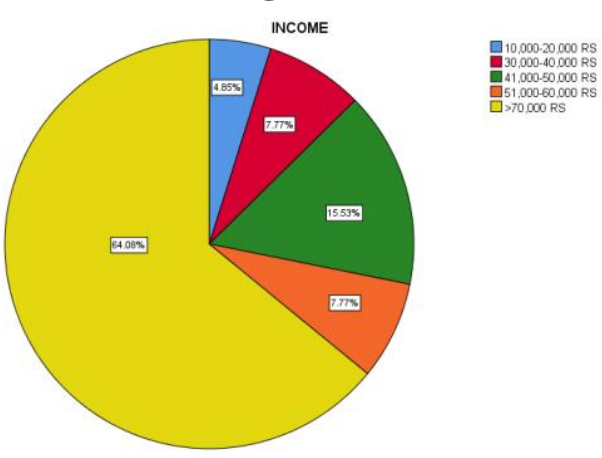

Figure 4

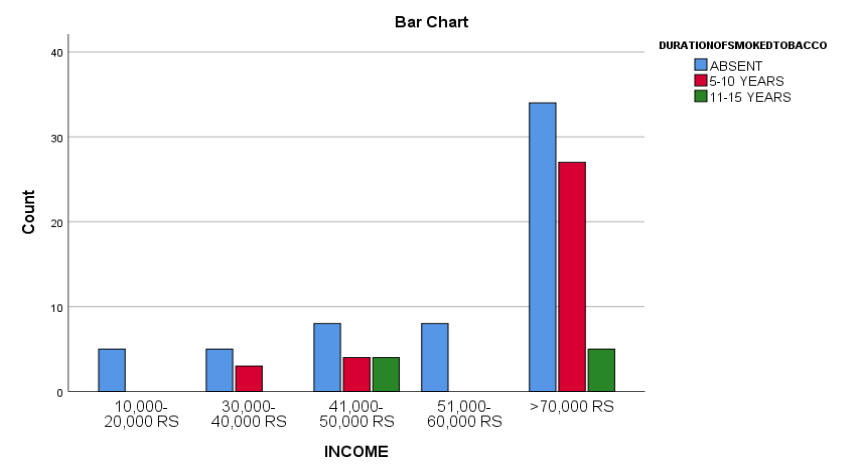

Figure 5

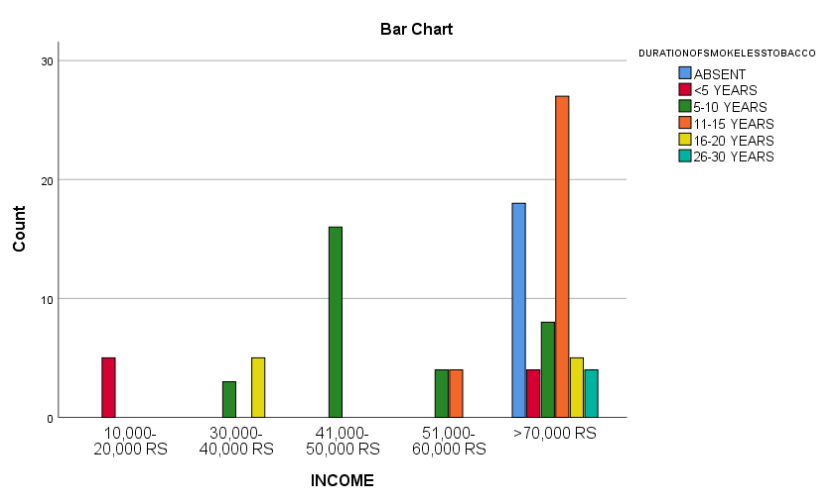

Figure 6

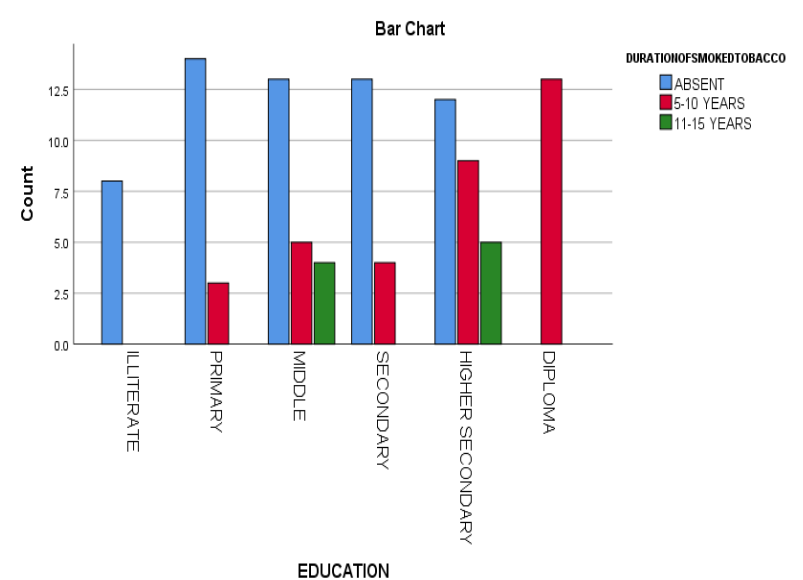

Figure 7

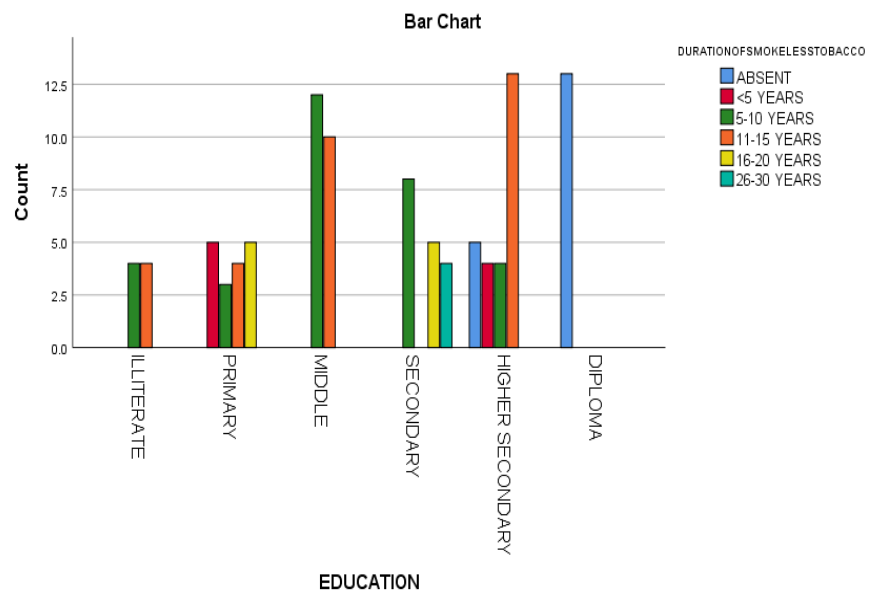

Figure 8

\section{Discussion and Recommendation}

In our study which was conducted in IMCHRC, Indore (M.P.) patients coming to psychiatry O.P.D. were interviewed and among them those that smoked cigarette took nicotine in oral forms were singles out and Fagerstroms Test for Nicotine Dependence applied on them, scored calculated \& statistical correlates calculated, among all the patients those who did take nicotine, their sociodemographic details were collected, consent 
forms signed by them \& amongst the smokers, Modified Fagerstroms Test For Nicotine Dependence for Smoke was applied, on the other hand those who took nicotine in any other forms to them Modified Fagerstroms Test for Nicotine Dependence for Smokeless forms of tobacco were applied, then data entry was done on SPSS and various tests were applied \& results calculated which will be discussed henceforth.

Ethical Permission- Institutional Ethical Committee Conflict of Interest- None

Source of Funding- Nil

\section{References}

1. Lasser, K., Boyd, J. W., Woolhandler, S., Himmelstein, D. U., McCormick, D., \&Bor, D. H. (2000). Smoking and mental illness: A population-based prevalence study. Journal of American Medical Association, 284, 2606 $-2610$.

2. Gupta, P. C., \&Hamner, J. E. (1992). Tobacco habits in India. In R. B. Bhonsle, P. R. Murti, \& P. C. Gupta (Eds.), Control of tobacco related cancers and other diseases. International Symposium, 1990 (pp. 25 - 46). Bombay7 Oxford University.

3. Subramanian, S. V., Nandy, S., Kelly, M., Gordon, D., \& Smith, G. D. (2004). Patterns and distribution of tobacco consumption in India: Cross sectional multilevel evidence from the 1998-9 national family health survey. British Medical Journal, 328, 801 806.

4. World Health Organization, 1997. Tobacco or Health: A Global Status Report. Geneva: WHO. 